\title{
A new method for evaluation nominal coefficient of friction and frictional forces in turning and inserts characterization using cutting forces profiles
}

\author{
Hamid Tebassi ${ }^{a^{*}}$, Mohamed Athmane Yallese ${ }^{a}$, Ikhlas Meddour ${ }^{a}$
}

${ }^{a}$ Mechanics and Structures Research Laboratory (LMS), May 8th 1945 University BP 41030 Algeria

\begin{tabular}{|c|c|}
\hline ARTICLE INFO & A B S T RACT \\
\hline $\begin{array}{l}\text { Article history: } \\
\text { Received } 6 \text { April, } 2015 \\
\text { Accepted } 19 \text { October } 2015 \\
\text { Available online } \\
28 \text { October } 2015 \\
\text { Keywords: } \\
\text { Tribology } \\
\text { Coefficient of friction } \\
\text { Normal forces } \\
\text { Frictional forces } \\
\text { Inserts characterization }\end{array}$ & $\begin{array}{l}\text { Serviceable engineering components not only rely on their bulk material properties but also on } \\
\text { the design and the characteristics of their surface. These characteristics influence directly the } \\
\text { surface quality of the machined products. In terms of surface roughness, the influence of the } \\
\text { tool material can be also caused by its tribological properties, i.e. a contact behavior between } \\
\text { cutting tool and workpiece. This study presents a formulation of the nominal's coefficient and } \\
\text { friction forces generated in machining between workpiece and cutting tool using cutting force } \\
\text { profiles. The obtained equations led to the evaluation of coefficient, frictional forces and } \\
\text { cutting inserts characterization in terms of better surface finish and lowest frictional forces. } \\
\text { Indeed, results show that the contact between cutting tool and workpiece depends on the } \\
\text { materials cutting tool nature, and that the cutting tool type can influences the surface roughness } \\
\text { of the machined surface. }\end{array}$ \\
\hline
\end{tabular}

\section{Introduction}

The word tribology is derived from the Greek word "tribos", which means "rubbing". Tribology covers the science of friction, lubrication and wear. The study of mechanics of friction dates back to the sixteenth century, almost immediately after the establishment of Newton's law of motion. It was noticed by several authors that the variation of friction and wear rate depends on the interfacial conditions such as normal load, geometry, relative surface motion, sliding speed, surface roughness of the rubbing surfaces, type of material, system rigidity, temperature, stick slip, relative humidity, lubrication and vibration (Archard, 1980; Bhushan, 2013). Because, contact surface damages can have various patterns: abrasion, fatigue, ploughing, corrugation, erosion and cavitations. Little fundamental understanding into solid mechanics aspects of tribology was gleaned until this century when measurements could be taken of surface roughness, and inferences made as to the real area of contact between surfaces. Even the smoothest surfaces are rough on the atomic scale

* Corresponding author.

E-mail addresses: tebassihamid@yahoo.fr (H. Tebassi) 
and contact only occurs at the tips of asperity peaks (Bowden \& Tabor, 1964). With similarly simplistic reasoning (Archard, 1953), a dimensionless wear coefficient $\boldsymbol{K}$, can be defined, which is a wear volume divided by real contact area times sliding distance. If the plastically deformed zone below the asperity is the same order as the real contact area, then $\boldsymbol{K}$ represents a ratio of worn volume to the plastically deformed zone.

There are two basic laws of friction. First Law is defined as: The friction is independent of the area of contact between the solids e.g. if one pulls a brick along a table, the friction is the same whether the brick is lying flat, or on its side, or standing on its end. Second Law is defined as: The friction is proportional to the load between the surfaces, e.g. if the load is doubled by putting a second brick on top of first, the force required to cause sliding is twice as great. If a pile of four bricks is used, the friction would be four times as great, and so on. Hence for any particular pair of surfaces, the ratio of friction per load is constant, and this constant is called the coefficient of friction $\boldsymbol{\mu}$. Hence, $\boldsymbol{\mu}$ equals frictional force per load.

Almost three centuries ago Charles Coulomb (1736-1806) established that kinetic friction does not depend on the sliding velocity. Later, more careful experiments showed that this law is only approximately valid (Braun \& Peyrard, 2011). In addition, (Xu et al. 2014; Byerlee, 1978; Drucker, 1953), obtained that along with the increased sliding distance, the friction force changed, as its first peak was the static friction force and its average values under the steady state were the dynamic friction force. The static friction coefficient $\boldsymbol{\mu}_{\boldsymbol{s}}$ and the dynamic friction coefficient $\boldsymbol{\mu}_{\boldsymbol{d}}$ were calculated as shown in Eq. (1) and Eq. (2):

$$
\begin{aligned}
& \mu_{\mathrm{s}}=\mathrm{F}_{\mathrm{s}} / \mathrm{F}_{\mathrm{n}}, \\
& \mu_{\mathrm{d}}=\mathrm{F}_{\mathrm{d}} / \mathrm{F}_{\mathrm{n}},
\end{aligned}
$$

where $\boldsymbol{F}_{\boldsymbol{s}}$ and $\boldsymbol{F}_{\boldsymbol{d}}$ are the static friction force and the dynamic friction force, respectively, and $\boldsymbol{F} \boldsymbol{n}$ is the normal force. Microscopically, when two rough surfaces come in contact, spherical tip of asperity would deform elastically and it will stick and could weld at the contact zone due to inter atomic adhesive force under loading condition. In addition, During slipping, if shearing strength at asperity junction is much more than bulk shear strength of one of the surface, fragment of material would be removed from the softer surface (Bera, 2013). Lorenz and Persson (2012) discussed the origin of static friction. They demonstrated how it can be reduced towards kinetic friction by the appropriate design of the sliding system. The basic idea is to use elastically soft solids and apply the external forces in such way that different parts of the contacting interface start to slip at different times during the (tangential) loading process. In contrast to previous work, (Farkas et al., 2005) take explicitly into account that the interlocked asperities are characterized by different threshold lengths with a probability distribution $\boldsymbol{p}(\boldsymbol{l})$, normalized as shown in Eq. (3):

$$
\int_{0}^{\infty} p(l) d l=1
$$

There is experimental evidence that this distribution is approximately Gaussian, centered on a characteristic length. Regarding the cited machining problematic, the main objective of the present work is to evaluate the coefficient of friction and frictional forces between cutting tool and workpiece when turning of Inconel 718 super alloy with two inserts (ceramic CC6050 and cermet 1525), by using the cutting force components profiles. This approach provides a new and simple idea which can be used to characterize the contact behavior at the interface of tool and workpiece and estimate the physical parameters whose describes this contact such as coefficient of friction, frictional force and dissipated energy. This technique can also provide an approach to decide which cutting tool is more appropriate for turning a given workpiece. 


\section{Material and Method}

\subsection{Mathematical formulations}

In many experimental investigations (Aouici et al. 2012, Axinte et al. 2001, de Agustina et al. 2013, ; Fetecau \& Stan 2012, Totis \& Sortino 2011, Segreto et al. 2012, Pal et al. 2014, Chinchanikar $\&$ Choudhury 2013, Tazehkandi et al. 2014, Bouacha et al. 2010) concerning turning process, the cutting force components (Fig.1), i.e. feed force $\boldsymbol{F}_{\boldsymbol{x}}$, thrust force $\boldsymbol{F}_{\boldsymbol{y}}$ and tangential force $\boldsymbol{F}_{\boldsymbol{z}}$ are expressed in function of the input parameters (cutting speed, feed rate, depth of cut ap, hardness, cooling pressure and etc.) as shown in Eq. (4), Eq. (5) and Eq. (6).

$$
\begin{aligned}
& F_{x}=C_{01}+\phi\left(X_{1}, X_{2}, X_{3} \ldots X_{n}\right), \\
& F_{y}=C_{02}+\phi\left(X_{1}, X_{2}, X_{3} \ldots X_{n}\right), \\
& F_{z}=C_{03}+\phi\left(X_{1}, X_{2}, X_{3} \ldots X_{n}\right),
\end{aligned}
$$

where $\boldsymbol{C}_{\boldsymbol{0} 1}, \boldsymbol{C}_{\boldsymbol{0} 2}$ and $\boldsymbol{C}_{\boldsymbol{0} 3}$ are the constants and $\boldsymbol{X}_{\boldsymbol{i}}$, are the explicative variables.

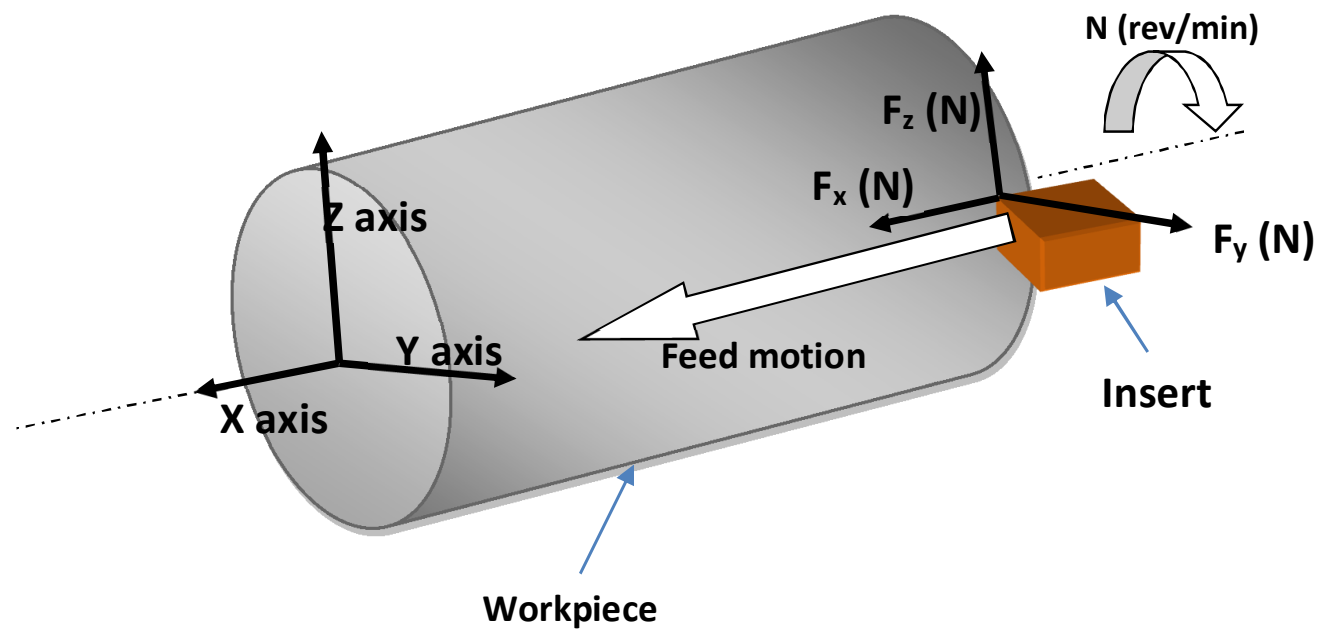

Fig.1. Force components when turning operation

In the case where only depth of cut $a p$ is considered as variable and all other parameters are kept constants, the cutting force components $\left(F_{x}, F_{y}\right.$ and $\left.F_{z}\right)$, are written as follow:

$$
\begin{aligned}
& \mathrm{F}_{\mathrm{x}}=\mathrm{C}_{1}+\zeta(\mathrm{ap}), \\
& \mathrm{F}_{\mathrm{y}}=\mathrm{C}_{2}+\zeta(\mathrm{ap}), \\
& \mathrm{F}_{\mathrm{z}}=\mathrm{C}_{3}+\zeta(\mathrm{ap}) .
\end{aligned}
$$

When the depth of cut $a p$ is equal zero we obtain the following equations:

$$
\begin{aligned}
& \mathrm{F}_{\mathrm{x}}=\mathrm{C}_{1}=\mathrm{F}_{\mathrm{x} 0}, \\
& \mathrm{~F}_{\mathrm{y}}=\mathrm{C}_{2}=\mathrm{F}_{\mathrm{y} 0}, \\
& \mathrm{~F}_{\mathrm{z}}=\mathrm{C}_{3}=\mathrm{F}_{\mathrm{z} 0 .}
\end{aligned}
$$

Thus, the tool is considered as a body sliding on the second one (workpiece) without cutting as

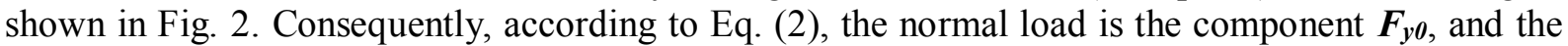
friction force is the resultant of $\boldsymbol{F}_{\boldsymbol{x} \boldsymbol{0}}$ and $\boldsymbol{F}_{\boldsymbol{z} \boldsymbol{0}}$ as shown in Eq. (13) and Eq. (14) (Xu et al., 2014; Maegawa, 2015; Zhong \& Tomanek, 1990). 
Friction force $=\sqrt{\left(F_{x 0}\right)^{2}+\left(F_{z 0}\right)^{2}}$.

By substituting the two terms in Eq. (2) the coefficient of dynamic friction can be formalized as fellow:

$$
\mu_{d}=\frac{\sqrt{\left(F_{x 0}\right)^{2}+\left(F_{z 0}\right)^{2}}}{F_{y 0}}
$$

So, according to the research cited on the literature (Farkas et al. 2005) and the Eq. (3), the obtained coefficient of dynamic friction shown in Eq. (15), can characterize the contact behavior between the insert and the workpiece in term of frictional force, and based on this coefficient of dynamic friction we can know the quantity of the dissipated energy when turning for new inserts. In addition, based on this reflection, it is possible to explain the difference between the roughness obtained by machining with different tools.

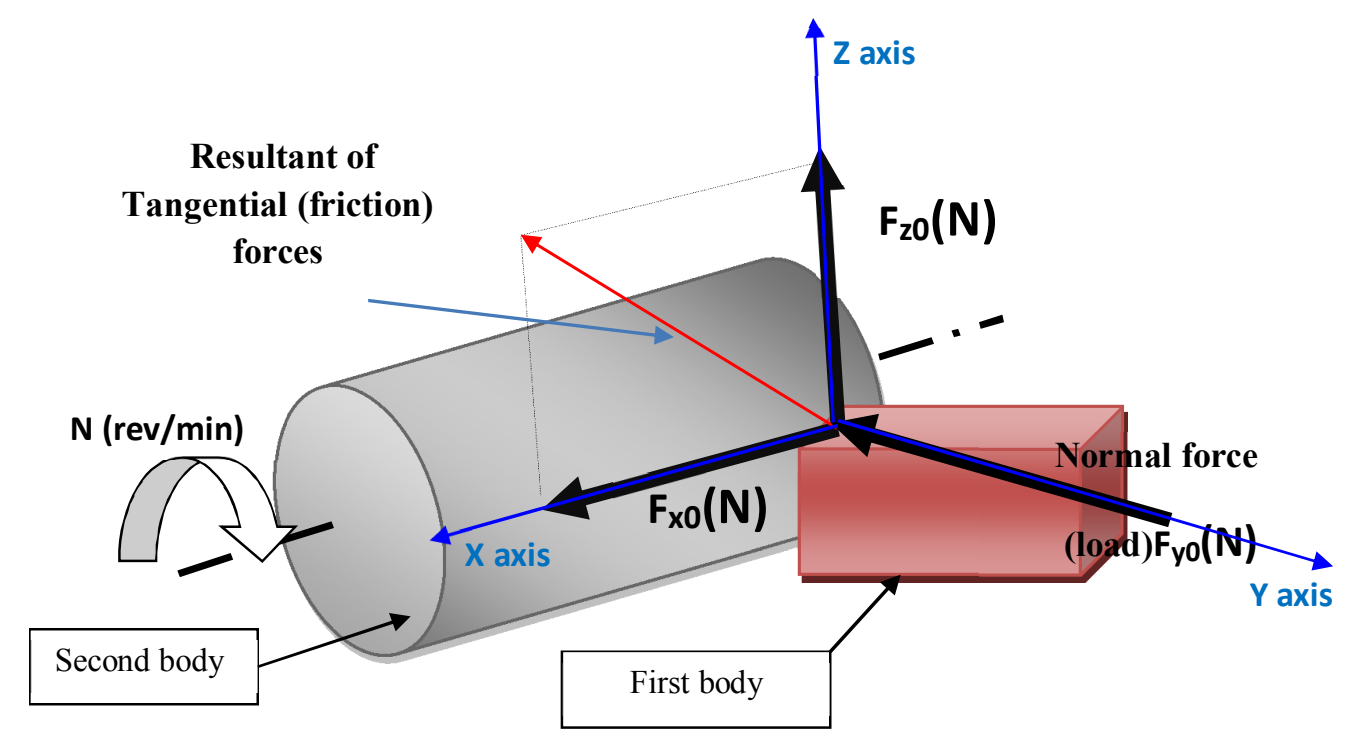

Fig. 2. Normal force (load) and resultant of tangential (friction) forces when turning operation

\subsection{Experimental validations}

The aim of this experimental work is to investigate the effect of cutting tool material on frictional coefficient, frictional forces and surface roughness.

In order to reach this objective, cutting speed $\boldsymbol{V} \boldsymbol{c}$, feed rate $\boldsymbol{f}$ and depth of cut $\boldsymbol{a p}$ are chosen respectively of $140 \mathrm{~m} / \mathrm{min}, 0.08 \mathrm{~mm} / \mathrm{rev}$ and $0.8 \mathrm{~mm}$ respectively. The workpiece material used in this study was Inconel 718 having $30 \mathrm{HRC}$ for hardness and the chemical composition: $0.08 \%$ for $\mathrm{C}$; $0.35 \%$ for $\mathrm{Mn} ; 0.35 \%$ for $\mathrm{Sn} ; 0.015 \%$ for $\mathrm{P} ; 0.015 \%$ for $\mathrm{S} ; 55 \%$ for $\mathrm{Ni} ; 21 \%$ for $\mathrm{Cr} ; 1 \%$ for $\mathrm{Co} ; 20 \%$ for $\mathrm{Fe} ; 3.3 \%$ for $\mathrm{Mo} ; 1.15 \%$ for $\mathrm{Ti} ; 0.15 \%$ for $\mathrm{Cu} ; 0.8 \%$ for $\mathrm{Al} ; 5.5 \%$ for $(\mathrm{Cb}+\mathrm{Ta})$.

The workpiece geometry is shown in Fig. 3. Machining operations have been achieved with a 6.6 KW spindle power TOS TRENCIN model SN40C lathe, in dry conditions. Cutting inserts having the standard designation (ISO) of SNGN 120408, commercialized by sandvik under (ceramic CC6050 and cermet 1525). The tool holder used in this experimental study has the standard designation of CSBNR2525M12 with following angles: $\chi_{\mathbf{r}}=75^{\circ}, \boldsymbol{\alpha}=6^{\circ}, \gamma=-6^{\circ}$ and $\lambda=-6^{\circ}$. Surface roughness 
measurements have been obtained directly on the tool machine and without disassembling the workpiece using a roughness meter (Surf test 301 Mututoyo).

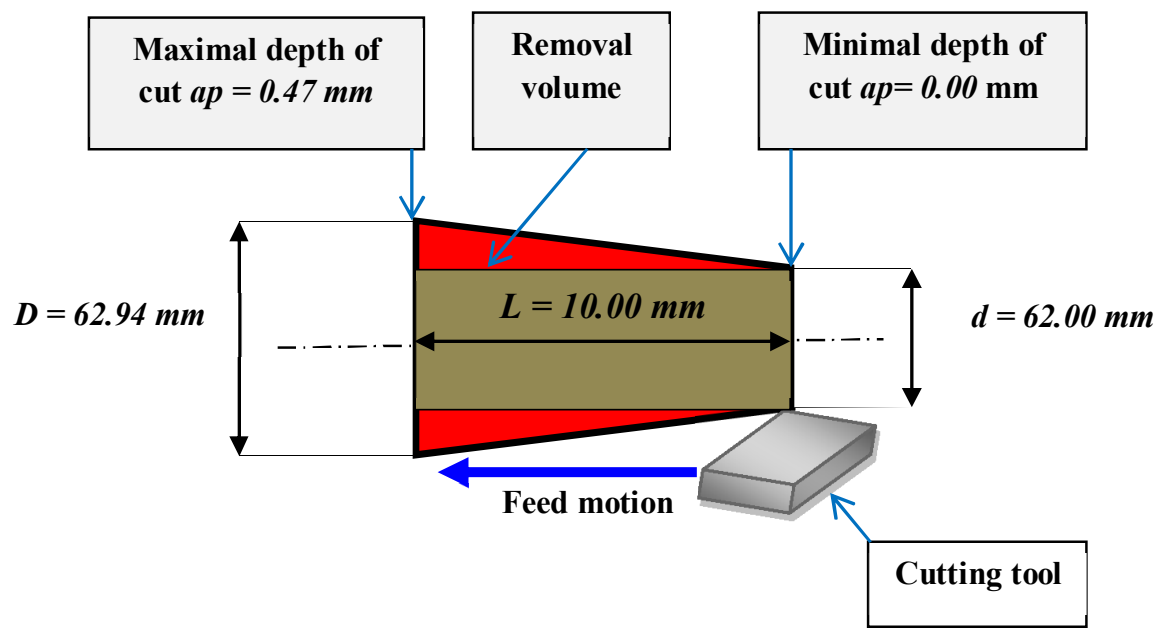

Fig. 3. Workpiece geometry and removal volume

Concerning cutting forces measuring, tool holder was mounted on a three-component piezoelectric dynamometer (Kistler 9257B). The measurement chain included a charge amplifier (Kistler 5019B130), data acquisition hardware (A/D 2855A3) and graphical programming environment (DYNOWARE 2825A1-1) for data analysis and visualization.

Fig. 4 and Fig. 5 show experimental results of cutting force components and its models in form of polynomial equation for ceramic CC 6050 and cermet 1525, respectively. The cutting force components models for cutting inserts (Ceramic CC 6050) are shown in Eq. (16), Eq. (17) and Eq. (18) as fellow:

$$
\begin{aligned}
& \text { Fx }(N)=-1 E-12(a p)^{4}+8 E-09(a p)^{3}-3 E-05(a p)^{2}+0,049(a p)+14,46 \\
& R^{2}=0.897 \\
& F y(N)=3 E-14(a p)^{4}+4 E-09(a p)^{3}-2 E-05(a p)^{2}+0,075(a p)+20,58 \\
& R^{2}=0.989 \\
& F z(N)=2 E-12(a p)^{4}-2 E-09(a p)^{3}-1 E-05(a p)^{2}+0,060(a p)-0,055 \\
& R^{2}=0.925
\end{aligned}
$$

Concerning the cutting force components models for cutting insert (Cermet 1525) are shown in Eq. (19), Eq. (20) and Eq. (21) as fellow:

$$
\begin{aligned}
& \text { Fx }(N)=-2 E-12(a p)^{4}+7 E-09(a p)^{3}-2 E-05(a p)^{2}+0,037(a p)+8,577 \\
& R^{2}=0.897 \\
& F y(N)=2 E-12(a p)^{4}-3 E-09(a p)^{3}-6 E-06(a p)^{2}+0,047(a p)+13,81 \\
& R^{2}=0.990 \\
& F z(N)=3 E-12(a p)^{4}-6 E-09(a p)^{3}-3 E-06(a p)^{2}+0,041(a p)+0,061 \\
& R^{2}=0.942
\end{aligned}
$$

Basing in Eq. (16), Eq. (17), Eq. (18), Eq. (19), Eq. (20) and Eq. (21), the components $F_{x 0}, F_{y 0}$ and $F_{z 0}$ for Ceramic CC 6050 and Cermet 1525 cutting tools are shown in Table 1. 
Coefficient of dynamic friction values when turning of Inconel 718 with Ceramic CC 6050 and Cermet 1525 cutting tools are calculated according to Eq. (15), and their values are shown in Table 1. This table shows also the measured surface roughness $\boldsymbol{R} \boldsymbol{a}(\mu \mathrm{m})$ after turning for both cutting tool.

Table 1

Results of friction forces, coefficient of friction and surface roughness

\begin{tabular}{cccccc}
\hline \multirow{2}{*}{ Cutting tool } & \multicolumn{3}{c}{ Normal and tangential forces } & Coefficient of friction & \multirow{2}{*}{$\mathrm{Ra}(\mu \mathrm{m})$} \\
& $\mathrm{F}_{\mathrm{x} 0}(\mathrm{~N})$ & $\mathrm{F}_{\mathrm{z} 0}(\mathrm{~N})$ & $\mathrm{F}_{\mathrm{y} 0}(\mathrm{~N})$ & $\mu_{d}$ & 0.43 \\
\hline Ceramic CC6050 & 14.46 & -0.055 & 20.58 & 0.7026 & 0.30 \\
Cermet 1525 & 8.577 & 0.061 & 13.81 & 0.6210 & \\
\hline
\end{tabular}

From results shown in Table 1, we can conclude that the increasing in coefficient of friction between inserts and machined workpiece led to increasing of measured surface roughness $\boldsymbol{R} \boldsymbol{a}(\mu \mathrm{m})$. Indeed, obtained $\boldsymbol{\mu}_{\boldsymbol{d}}$ when turning of Inconel 718 with CC6050 have value of 0.7026 and $\boldsymbol{R} \boldsymbol{a}=0.43$ $\mu \mathrm{m}$. On the other hand, $\boldsymbol{\mu}_{\boldsymbol{d}}$ value is to 0.6210 when turning of Inconel 718 using Cermet 1525 insert and $0.30 \mu \mathrm{m}$ for $\boldsymbol{R} \boldsymbol{a} \mu \mathrm{m}$.

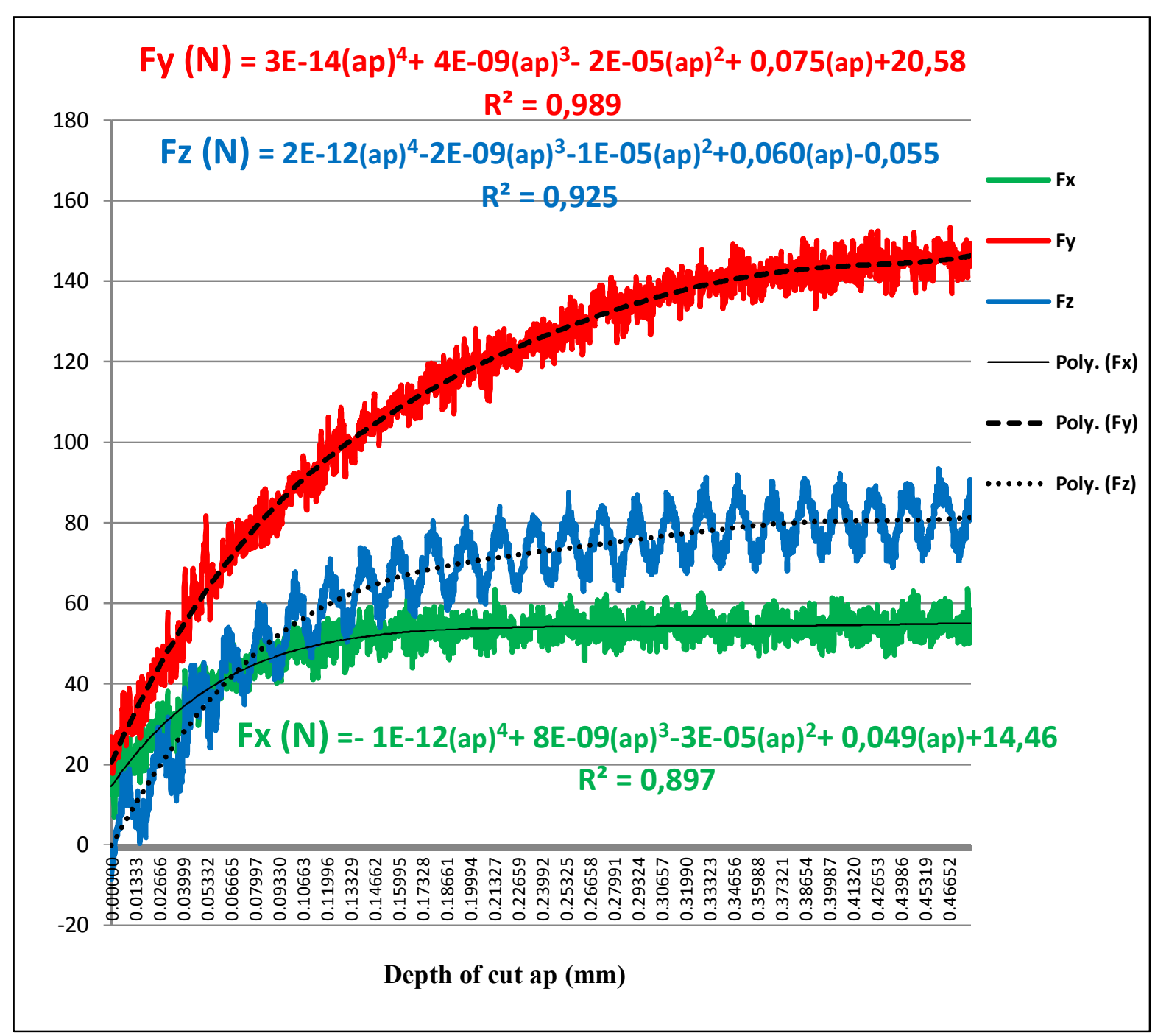

Fig. 4. Cutting force components when turning of Inconel 718 with using ceramic CC6050 with cutting condition of $140 \mathrm{~m} / \mathrm{min}$ for cutting speed $\boldsymbol{V}$ and $0.08 \mathrm{~mm} / \mathrm{rev}$ for feed rate $\boldsymbol{f}$ 


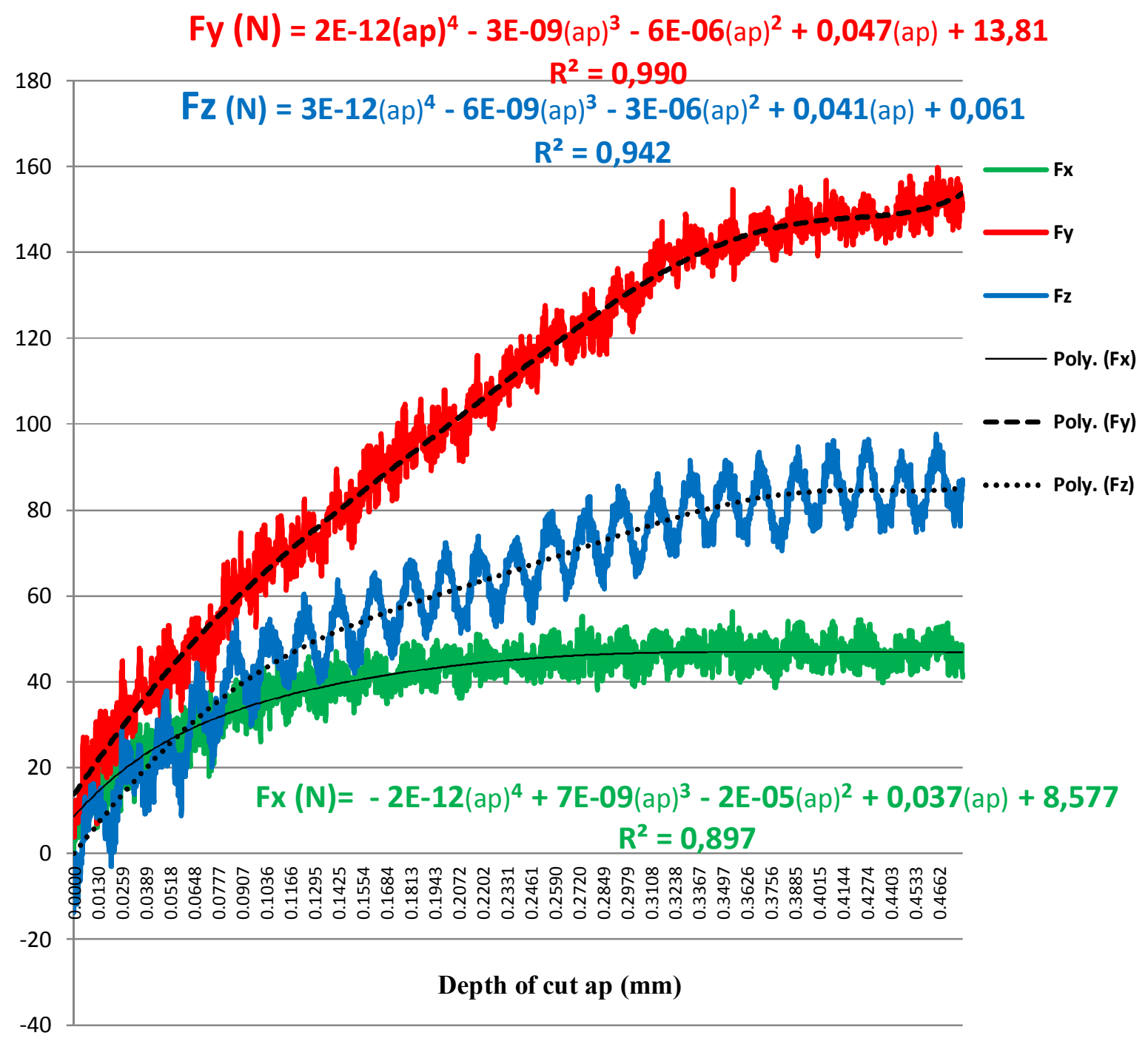

Fig. 5. Cutting force components when turning of Inconel 718 with using Cermet 1525 with cutting condition of $140 \mathrm{~m} / \mathrm{min}$ for cutting speed $\boldsymbol{V} \boldsymbol{c}$ and $0.08 \mathrm{~mm} / \mathrm{rev}$ for feed rate $\boldsymbol{f}$

\section{Conclusions}

This work which involves a formulation of coefficient and frictional forces in turning operation, can leads to the following conclusions:

1. During turning, each new insert is characterized by its own coefficient of friction which depends primarily on the machined material. Indeed, Ceramic CC 6050 and Cermet 1525 presents different coefficients of friction, with the values of 0.621 when turning of Inconel 718 with Cermet 1525 and 0.7026 using Ceramic CC 6050 for turning operation.

2. The dynamic friction represents the dissipated energy by the tool when turning, which influences surface finish.

3. Increasing of dynamic coefficient of friction led to increase in roughness $\boldsymbol{R} \boldsymbol{a}(\mu \mathrm{m})$ of machined surface.

4. The insert (Cermet 1525) having lowest coefficient of friction and better surface roughness than (Ceramic CC 6050) insert.

5. In future, researches are focused in the theoretical formulation and experimental validation of coefficient of friction and dissipated energy for worn inserts when turning. 
Regarding the current research, the new approach proposed can be considered as a powerful and can offer to scientific researcher's as well industrial metalworking a helpful to evaluate friction coefficient and frictional forces and characterizes given inserts more appropriate for turning.

\section{Acknowledgements}

This work was achieved in the laboratories LMS (University of Guelma Algeria). The authors would like to thank the Algerian Ministry of Higher Education and Scientific Research (MESRS) and the Delegated Ministry for Scientific Research (MDRS) for granting financial support for CNEPRU Research Project, CODE: A11N01UN240120140013 (University 08 May 1945, Guelma).

\section{References}

Aouici, H., Yallese, M. A., Chaoui, K., Mabrouki, T., \& Rigal, J. F. (2012). Analysis of surface roughness and cutting force components in hard turning with CBN tool: prediction model and cutting conditions optimization. Measurement, 45(3), 344-353.

Axinte, D. A., Belluco, W., \& De Chiffre, L. (2001). Evaluation of cutting force uncertainty components in turning. International Journal of Machine Tools and Manufacture, 41(5), 719-730.

Archard, J. F. (1980). Wear theory and mechanisms. Wear Control Handbook, 58.

Archard, J. (1953). Contact and rubbing of flat surfaces. Journal of Applied Physics, 24(8), 981-988.

de Agustina, B., Bernal, C., Camacho, A. M., \& Rubio, E. M. (2013). Experimental analysis of the cutting forces obtained in dry turning processes of UNS A97075 Aluminium Alloys. Procedia Engineering, 63, 694-699.

Bera, B. (2013). Adhesive wear theory of micromechanical surface contact. International Journal of Computational Engineering Resources, 3(3), 73-78.

Bhushan, B. (2013). Principles and applications of tribology. John Wiley \& Sons.

Byerlee, J., (1978). Friction of rocks. Pure and applied geophysics, 116(4-5), 615-626.

Bowden, F. P., \& Tabor, D. (1964). The friction and lubrication of solids. Oxford: Clarendon press.

Bouacha, K., Yallese, M. A., Mabrouki, T., \& Rigal, J. F. (2010). Statistical analysis of surface roughness and cutting forces using response surface methodology in hard turning of AISI 52100 bearing steel with CBN tool. International Journal of Refractory Metals and Hard Materials, 28(3), 349-361.

Braun, O. M., \& Peyrard, M. (2011). Dependence of kinetic friction on velocity: Master equation approach. Physical Review E, 83(4), 046129.

Chinchanikar, S., \& Choudhury, S. K. (2013). Effect of work material hardness and cutting parameters on performance of coated carbide tool when turning hardened steel: An optimization approach. Measurement, 46(4), 1572-1584.

Drucker, D. C. (1953). Coulomb friction, plasticity, and limit loads (No. TR-85). BROWN UNIV PROVIDENCE RI DIV OF APPLIED MATHEMATICS.

Farkas, Z., Dahmen, S. R., \& Wolf, D. E. (2005). Static versus dynamic friction: the role of coherence. Journal of Statistical Mechanics: Theory and Experiment, 2005(6), P06015.

Fetecau, C., \& Stan, F. (2012). Study of cutting force and surface roughness in the turning of polytetrafluoroethylene composites with a polycrystalline diamond tool. Measurement, 45(6), 1367-1379.

Lorenz, B., \& Persson, B. N. J. (2012). On the origin of why static or breakloose friction is larger than kinetic friction, and how to reduce it: the role of aging, elasticity and sequential interfacial slip. Journal of Physics: Condensed Matter, 24(22), 225008.

Maegawa, S., Itoigawa, F., \& Nakamura, T. (2015). Effect of normal load on friction coefficient for sliding contact between rough rubber surface and rigid smooth plane. Tribology International, 92, 335-343.

Pal, A., Choudhury, S. K., \& Chinchanikar, S. (2014). Machinability assessment through experimental investigation during hard and soft turning of hardened steel. Procedia Materials Science, 6, 80-91.

Segreto, T., Simeone, A., \& Teti, R. (2012). Chip form classification in carbon steel turning through cutting force measurement and principal component analysis. Procedia CIRP, 2, 49-54.

Tazehkandi, A. H., Pilehvarian, F., \& Davoodi, B. (2014). Experimental investigation on removing cutting fluid from turning of Inconel 725 with coated carbide tools. Journal of Cleaner Production, 80, 271-281.

Totis, G., \& Sortino, M. (2011). Development of a modular dynamometer for triaxial cutting force measurement in turning. International Journal of Machine Tools and Manufacture, 51(1), 34-42.

Xu, M., Li, L., Wang, M., \& Luo, B., (2014). Effects of surface roughness and wood grain on the friction coefficient of wooden materials for wood-wood frictional pair. Tribology Transactions, 57(5), 871-878.

Zhong, W., \& Tomanek, D. (1990). First-principles theory of atomic-scale friction. Physical Review Letters, 64(25), 3054. 